\title{
Effectiveness of group Cognitive - Behavioral therapy on reducing depression
}

\author{
Zeinab Khairkhah*, Ahmad Borjali, Faramarz Sohrabi \\ Department of Psychology, Allameh Tabatabaee University, Tehran, Iran \\ *E-mail address: kheirkhah85@yahoo.com
}

\begin{abstract}
The present research was done with the aim of determining the effectiveness of group Cognitive - Behavioral therapy on reducing depression and its subscales (emotional symptoms, cognitive symptoms and physical symptoms) among the wives of the martyrs in the city of Tehran. First, 200 wives of the martyrs were randomly selected from among the wives of the martyrs who had referred to the counseling center of the Foundation of Martyrs and the questionnaire of depression was administered on them. The subjects whose level of depression was higher than the average level were determined and from among them 60 people were randomly chosen and later they were divided into two equal groups and from these two groups, by drawing one group was selected as the experimental and the other was selected as the control group. In the pretest stage, the questionnaire was administered on the subjects and the experimental group was placed under training, i.e. group cognitive-behavioral therapy, while the control group received no such therapy. In the posttest stage, the questionnaire of depression was carried out on both groups and one month later, the follow up stage was administered. Findings revealed that training group cognitive-behavioral therapy was effective on decreasing depression on the wives of the martyrs in Tehran. Findings also indicated depression among the experimental group and in the follow up stage they enjoyed necessary constancy. It is concluded that the group cognitive-behavioral therapy has considerably diminished depression among the wives.
\end{abstract}

Keywords: Depression; Wives of the martyrs; cognitive - behavioral therapy

\section{INTRODUCTION}

War involves different impacts, where these impacts in accordance with the duration of the war, its intensity and prevalence have various manifestations. Physical disabilities and mental side effects resulting from war was one of the manifestations that we have been observing in the scenes of war and later years among the survivors of the war and their relatives quite considerably (Vafaei \& Khosravi, 2009). One of the main events and perhaps one of the events in the past three decades in Iran is the imposed war. War is a category that leaves positive and negative impacts in any society of negative consequences we can refer to killing, being killed, injury and captivity, devastation and underdevelopment, losing parents and children and loneliness and .... . In any of these phenomena, human forces have been involved who have suffered huge material and mental losses.

In our country, following the eight year old war, we have observed these implications and one of the negative consequences has been the loss of the guardian of the family, where this loss is painful and excruciating for the wife. With the martyrdom of the sublime martyrs, 
their wives assumed to manage family affairs, take charge to raise children and also to eliminate economic problems of the family by themselves. However, this loneliness and cumbersome responsibility in life as well as mental pressures inflicting on them from different areas resulted in dysfunctions and disorders in the social life trend of the wives of the martyrs and caused various mental and mental shortcomings. Death though be unexpected and unsolicited is a fatal shock to the relatives of the martyr. According to the Koran's verses as well as various holy sayings, those who are slain on the way of God and defending the values are called martyrs and this word, not only peculiar to the Islamic religion but also existed in pre Islam communities.

However, the survivors of these people are faced with constraints in their personal and social lives. Of course, due to the fact that in the society special homage is paid for the martyr and martyrdom, however this subject will engender in depression and lack of interest among the wives of the martyrs. In order to support and continue the epic, cultural and doctrinal moves and compensate for the constraints resulting from the absence of the caretaker of the family for raising the children, the Foundation of Martyrdom and Veterans Affairs have placed these people under its coverage.

However, it appears despite the supports by the mentioned institutions, attention and elimination of all the mental and psychic damages these people had experienced after the martyrdom of their husbands were not alleviated by these institutions, while the burden of responsibility for raising the children brought about doubled problems. On the other hand, in different cultures, women encounter limitations and in the Iranian culture, too women without husbands are faced with limitations where these limitations will engender huge amounts of stress and tensions and depression in the end. On the other hand, caretakers due to some reasons including absence of prior experience and unfamiliarity with psychological perspectives, social psychology are not able to understand all the mental and psychological problems of them (Kheirkhah, 2010).

Death of the husband in any form, including a natural death or martyrdom is very dangerous and stressful, and these pressures in life will result in lowering disposition and depression. Emotions and feelings related with war being suppressed by the survivors of the war, especially by the wives of the martyrs in order to compatibility and meet necessary needs for a normal life will once again appear in a period of life (especially with rising age) and thus they result in emergence of symptoms and depression signs. Some factors may be involved in initiating these signs and facilitating their appearance, where losing members of the family and friends and experience of loss are such factors. These stressful experiences of losses will in turn result in reduction and loss of the familial and social support networks (Coleman, 1986). Depression, more than other disorders is related with the mental health state and the extent to which the survivors of the war enjoy the social support (Hyer et al, 1999).

One of the characteristics of the depressed people is their disappointment which is in the form of sighing and saying "I can't ", indicating a negative cognitive framework and feeling of inadequacy related with a general and fixed attribution style. Usually, those who have higher level of disappointment are more likely to appear as a person with problems; they have lower self-concept and feel more anxiety. They have fixed mind of all or nothing that hinders problem solution; in fact disappointment will engender the patient to assess his /her experiences negatively and falsely and more he/she considers sinister and worrisome results for his problems and conducts. Mandler (1992), thought of two things as enough reasons for depression, one is negative expectations about unpleasant and valuable consequences and the other is expectation of inability concerning changing or preventing these negative events. Thus, contrary to the fact that disappointment is the necessary part of depression, but it is not enough for creating it. Disappointment is the subset of inability and is an expectation. If we try to compare the theory of disappointment with inability, we should state that the theory of 
inability due to the fact enough condition that the person cannot change his situation has appeared. Thus, disappointment could be considered to be the sole condition of depression. To explain how a person is affected with disappointment and subsequent depression, Mandler adds; this hypothetical causative chain starts with this perception that negative occurrences will happen, but positive occurrences won't happen. Negative events serve as the starting situations that peoepl feel despair (Quoted by Kheirkhah, 2010).

The presence of parents in the family will significantly contribute to the educational performance and emotional, moral, social and political growth of the children. Given the existing circumstances, mother should for compensating this vacuum in life tolerate more pressures, though many factors are involved in the cultural and social growth, particularly in the mental and psychic security of the wives and these issues will endanger personal and social life of the peoepl (Goldenberg and Goldenberg, 2009). Bowlby (1980) maintains the psychotherapy applicants are those who feel trapped with their grief. They believe this experience won't come to an end, mourning won't end and to go through it, they need help.

Also, grief is embodied as the foundational reason of types of physical and mental disorders. People trying to take care of their mental and physical health are mostly ignorant of the fact the issue of grief could be the core reason of their peculiar mental and physical states. Teseng (1978) estimates that more than \%10-\%15 of the people at the mental health clinics of the state of Massachusetts' public hospitals, have faced with some unsettled grief in their post special psychological state (Quoted by Kheirkhah, 2010).

Zisook et al (1997) found out that \%17 of the patients who enter outpatient psychotherapy facilities centers of California have faced with some unsettled grief while assessing themselves. Psychiatrist Bowlby (1980), while approving this phenomenon states that clinical experience and study of observations concerning this important belief leave no room for doubt that most psychiatry diseases are embodiment of pathologic mourning. Despite this disease includes most cases like anxiety, depression making patience and hysteria and is more than one disorder (Bowlby, 1980), there are studies in literature that point out the effects of grief on illnesses and fatality; this point holds true for illnesses associated with marital bereavement and loss of spouse.

Additionally, war will prepare a situation for more study and the researchers can in different areas achieve and discover lawfulness in relation with humans which are peculiar to the post war life. This will add to the human knowledge in this area. Research results by Edelman et al (1999) with the subject of investigating the effectiveness of the cognitivebehavioral therapy on reducing depression and increasing self-esteem in patients affected with progressive breast cancer indicated that the group cognitive-behavioral therapy was effective on reducing depression and dispositional disorders.

Research results by Darvishi (2009), with the subject of applying mental imagery and relaxation on reducing anxiety, depression and increasing life expectancy among the women affected with breast cancer of the Golestan hospital in Ahvaz indicated that the cognitivebehavioral therapy had been significantly effective in decreasing anxiety and increasing life expectancy of the aforementioned patients. Researches reveal the effectiveness of cognitive therapy on disorders and depression (Hamid et al, 2011; Siegel et al, 2011; Smith et al, 2009). Research by Khaledian et al (2013), titled the effectiveness of group cognitive-behavioral therapy on reducing depression and increasing life expectancy in the syndrome of empty net demonstrated that the therapy in question was effective in reducing depression.

The research performed in Iran, in relation with the extent of depression among the wives of martyrs (Alipour \& Raeesinejad, 2001; Roshan \& Shakeri, 2010) prepared a situation for other researches to be done, thus we can get documented answers to our questions. Will the death of the husband engender depression? And can we diminish depression by educating the behavioral-cognitive therapy. According to the content above the 
paper aims to determine the effectiveness of group Cognitive - Behavioral therapy on reducing depression and its subscales (emotional symptoms, cognitive symptoms and physical symptoms) among the wives of the martyrs in the city of Tehran.

\section{METHODOLOGY}

First, 200 wives of the martyrs were randomly selected from among the wives of the martyrs who had referred to the counseling center of the Foundation of Martyrs and the questionnaire of depression was administered on them. The subjects whose level of depression was higher than the average level were determined and from among them 60 people were randomly chosen and later they were divided into two equal groups and from these two groups, by drawing one group was selected as the experimental and the other was selected as the control group. After the pretest, the experimental group under the name of training group was placed under 12, 120 minute sessions in line with the practical manual of group cognitive-behavioral therapy, while the control group received no such intervention. In the posttest stage, the depression questionnaire was performed on both groups (dependent variable) and one month after that the follow-up stage was administered.

\section{Measurement tools}

In this research the standardized depression questionnaire by Beck was applied.

\section{- Beck depression questionnaire}

Depression is a state of disposition which is followed by reduced self-respect, feeling of insufficiency, unworthiness and unfavorable impression of the self. From among the questionnaires prepared for the evaluation of depression, the Beck depression questionnaire (BAI) is of the most appropriate tools for appraising states of depression. This questionnaire has 21 items that measures physical, behavioral and depression symptoms. Each item has 4 choices which is scored from 0-3, and it determines varied degrees of depression from mild to severe. The maximum score of this questionnaire is 63 while 0 is the least score. The average coefficient of reliability and validity of the tool is $91 \%$ (Hasani, 2008).

\section{- Training group cognitive-behavioral therapy}

In this paper, too the practical group cognitive therapy manual (Michael Ferry, 2005), was employed and the experimental group was placed under six weeks of training, each week two sessions, a total of 12 sessions and each sessions for 120 minutes. One session was considered for getting the group familiar where a total of 13 sessions was administered. 


\section{RESULTS}

a) Prior stage to the group cognitive-behavioral therapy

Table1. Statistical features of the depression component in the experimental and control groups in the stage prior to the group cognitive-behavioral therapy.

\begin{tabular}{|c|c|c|c|c|}
\hline & \multicolumn{2}{c}{ Experimental group } & \multicolumn{2}{c|}{ Control group } \\
\hline Depression subscales & Average & $\begin{array}{c}\text { Standard } \\
\text { deviation }\end{array}$ & Average & $\begin{array}{c}\text { Standard } \\
\text { deviation }\end{array}$ \\
\hline Emotional symptoms & 11.10 & 3.42 & 11.67 & 2.25 \\
\hline Cognitive symptoms & 12.13 & 3.45 & 11.80 & 3.04 \\
\hline Physical symptoms & 8.13 & 2.74 & 8.23 & 2.11 \\
\hline Total depression & 31.37 & 7.57 & 31.70 & 5.63 \\
\hline
\end{tabular}

Table (1) indicates that there is no tangible difference between the average depression and its subscales in the prestage of the cognitive-behavioral therapy between the two groups and approximately the average scores of the mentioned components is close.

b) Stage after the group cognitive-behavioral therapy

Table 2. Statistical features of the depression component in the experimental and control groups stage after the group cognitive-behavioral therapy.

\begin{tabular}{|c|c|c|c|c|}
\hline & \multicolumn{2}{c}{ Experimental group } & \multicolumn{2}{c|}{ Control group } \\
\hline Depression subscales & Average & $\begin{array}{c}\text { Standard } \\
\text { deviation }\end{array}$ & Average & $\begin{array}{c}\text { Standard } \\
\text { deviation }\end{array}$ \\
\hline Emotional symptoms & 0.30 & 0.53 & 11.57 & 3.15 \\
\hline Cognitive symptoms & 0.33 & 0.55 & 11.17 & 3.01 \\
\hline Physical symptoms & 0.30 & 0.60 & 8.13 & 1.63 \\
\hline Total depression & 0.93 & 1.17 & 30.87 & 6.32 \\
\hline
\end{tabular}

Table (2) indicates that there is tangible difference between the average depression and its subscales in the post stage of the cognitive-behavioral therapy between the two groups, such that the average depression and its subscales among the experimental group were much less than that of the other group. Considering the variations of the overall average depression among the experimental people in the stage after the group cognitive-behavioral therapy, the average scores of peoepl was reduced to $0 / 93$ from $31 / 37$, indicating the positive effects of the therapy on the experimental people, lowering their depression level extremely. 
Table 3. Covariance analysis of inter group impacts of reducing depression in the wives of the martyrs between the experimental and control groups.

\begin{tabular}{|c|c|c|c|c|c|c|}
\hline $\begin{array}{c}\text { Sources of } \\
\text { change }\end{array}$ & SS & DF & MS & F & $\begin{array}{c}\text { P-value } \\
\text { Sig. }\end{array}$ & Effect size \\
\hline $\begin{array}{c}\text { Depression } \\
\text { pretest }\end{array}$ & 77.985 & 1 & 78.985 & 4.026 & .050 & .066 \\
\hline Group & 13379.118 & 1 & 13379.118 & 681.907 & .000 & .923 \\
\hline Error & 1118.348 & 57 & 19.620 & & & \\
\hline
\end{tabular}

Table (3) Could be inferred as demonstrating training group cognitive-behavioral therapy has significant effects on reducing depression among the subjects under study. The overall reformed effects size is $0 / 923$ where this extent is in accordance with the Cohen criteria at a higher level, being statistically significant $(\mathrm{P}<0 / 05)$.

c) Follow-up stage

Statistical features include average and standard deviation of depression and its subscales among experimental group people in the post stage and follow-up stage are provided in the following table.

Table 4. Statistical features of the component of depression in the experimental group in the post stage and follow-up stage.

\begin{tabular}{|c|c|c|c|c|}
\hline \multicolumn{2}{c}{ Posttest } & \multicolumn{2}{c|}{ Follow-up } \\
\hline Depression subscales & Average & $\begin{array}{c}\text { Standard } \\
\text { deviation }\end{array}$ & Average & $\begin{array}{c}\text { Standard } \\
\text { deviation }\end{array}$ \\
\hline Emotional symptoms & 0.30 & 0.53 & 0.23 & 0.43 \\
\hline Cognitive symptoms & 0.33 & 0.55 & 0.10 & 0.31 \\
\hline Physical symptoms & 0.30 & 0.60 & 0.20 & 0.41 \\
\hline Total depression & 0.93 & 1.17 & 0.55 & 0.63 \\
\hline
\end{tabular}

Table 5. Results of dependent $t$ test for comparing the variations of average depression of the experimental group in the post stage of group training and follow-up.

\begin{tabular}{|c|c|c|c|c|c|c|c|}
\hline \multirow{3}{*}{ Variable } & \multicolumn{4}{|c|}{ Experimental group } & \multirow{2}{*}{\multicolumn{3}{|c|}{ Dependent $t$ test }} \\
\hline & \multicolumn{2}{|c|}{$\begin{array}{c}\text { Experimental group } \\
\text { posttest }\end{array}$} & \multicolumn{2}{|c|}{$\begin{array}{l}\text { Experimental group } \\
\text { follow-up }\end{array}$} & & & \\
\hline & Average & $\begin{array}{c}\text { Standard } \\
\text { deviation }\end{array}$ & Average & $\begin{array}{l}\text { Standard } \\
\text { deviation }\end{array}$ & $\begin{array}{c}\mathrm{t} \\
\text { ratio }\end{array}$ & $\begin{array}{c}\text { Freedom } \\
\text { degree }\end{array}$ & Sig. P \\
\hline Depression & 0.93 & 1.17 & 0.55 & 0.63 & 1.589 & 28 & .123 \\
\hline
\end{tabular}


Table (4) demonstrates there is no tangible differences between the average component of depression and its subscales in the post stage and follow-up stage in the experimental group, such hat it varied from $0 / 93$ to $0 / 36$.

Results of Table (5) Indicates that based on the $t$ test statistic, the resulting extent of $t$ in depression (1/589) is smaller than the critical table $t(2 / 04)$ with the freedom degree of 28 , hence, the average difference of depression scores in the experimental group between the posttest stage and follow-up stage is not significant $(\mathrm{P}>0 / 05)$.

\section{DISCUSSION}

The present research was done with the aim of determining the effectiveness of group Cognitive -Behavioral therapy on reducing depression and its subscales (emotional symptoms, cognitive symptoms and physical symptoms) among the wives of the martyrs in the city of Tehran, where in accordance with the research findings we can conclude that group cognitive-binaural therapy is effective on reducing depression. These findings are in line with the findings by Darvishi (2009), Edelman et al (1999), Hamid et al (2011), Seigle et al (2011), Smith et al (2009), and Khaledian et al (2013). To explain the findings we can say that the Group Cognitive - Behavioral Therapy (CBT) OR Cognitive Therapy (CT) are employed for treating most psychological problems and psychiatric disorders, including controlling anger and dispositional anxiety and creating schizophrenia. The various scientific findings obtained in recent years have raised cognitive therapy as the effective method for curing most psychological problems and psychiatric disorders, such as disorder of fear and phobia, fear of open and high places and major depression. Based on scientific findings cognitive therapy as a psychotherapeutic approach is effective on reducing peoples suffering from mental illnesses (Ferry, 2005).

The cognitive-behavioral approach attempts to emphasize on the operational description of tye concepts and validation of treatment quite empirically. Also, to attain the retest of the findings, the therapeutic method should be ascertained on the basis of operational definitions and its impacts should be assessed with the help of reliable and objective criteria. The major goal of treatment is to help the patient such that he/she can create favorable changes in his/her life. Thus, emphasis in treatment is directed on providing a chance for new adaptation learning and for creating changes in an environment outside of the clinical area. Problem solution consists of an inherent part of treatment. All the therapeutic aspect is explained for the patient. The therapist and patient attempt to establish a mutual relationship with one another to create strategies for dealing with the clearly defined issues. To Lihi (2008) it's been for 20 years that the cognitive model has gained importance and it appears it has been more widespread more than any other models. Li Hi considers the popularity of tis model for the following reasons:

This approach is an effective, centralized and practical treatment for special disorders. It is not mysterious and complex, such that it will facilitate the transference of knowledge from the therapist to the patient. It is an economical therapy. The CBT is a psychotherapy that helps people, while understanding the thoughts and feelings affecting their lives attain their goals. The CBT is employed for treating most disorders, including depression and anxiety. (Lihi, 2008). In line with the findings of the present research, it is recommended that this research and the other researches alike are provided to the Centers of the Foundation of Martyrdom so that they are become familiar with the effects of this type of therapy.

Also, performing these types of research is recommended for ascertaining the effectiveness of the CBT on reducing depression. 


\section{CONCLUSION}

Though the wives of our martyrs differ with the people involved in war in terms of religious beliefs, martyrdom morale, martyrdom being a value and respect of the society for the martyr and their relatives, hence the unwanted effects and side effects resulting from the mental and physical problems affecting then wives of the martyrs should not be neglected. Thus, the present research is an attempt to gauge the effectuality of the CBT on reducing depression of the wives of the martyrs, so that a step is taken to better realize and understand their conditions. It is concluded that the CBT is significantly effective on diminishing depression.

\section{References}

[1] Alipoor, M., \& Raeesinejad, M. (2001). Investigating the extent of depression among the wives of martyrs in Province of Shiraz, Doctoral dissertation, Shiraz Medical Sciences University.

[2] Bowlby, J. (1980). Attachment and lossoadhesand depression. New York. Basic book.

[3] Coleman, P. G. (1986). Aging and reminiscence processes: Social and clinical implications. New York: Wiley: 80-100.

[4] Darvishi, H. (2009). Investigating the applicability of mental imagery and relaxation on reducing anxiety, depression of hospital and increasing life expectancy among the women affected with progressive breast cancer in the Golestan hospital of Ahvaz, M.A. thesis.

[5] Edelman, S., Bell, D. R., \& Kidman, A. D. (1999). Group CBT Versus Supportive Therapy With Patients Who Have Primary Breast Cancer, Journal of Cognitive Psychotherapy, 13(3): 189-202.

[6] Ferry, M. (2005). Practical manual of group CBT, Trans by Masood Mohamadi, Robert Farnam, Tehran: Roshd publication.

[7] Goldenberg, I., \& Goldenberg, H. (2008). Family therapy, Trans, by Hamid Reza Hussein Shokoohi, Syamak Naghshbandi, Elham Arjomand, Tehran: Nashre Ravan Publication.

[8] Hamid, N., Beshkide, K., Eidibayegi, M., \& Dehghanizade, Z. (2011). Investigating the effectiveness of religion centered CBT on the depression of divorced women, Quarterly of counseling and family therapy, 1(1): 54-64.

[9] Hasani, F. (2008). Comparing the internal effectiveness of the CBT couple therapy and emotion-centered CBT on depression and anxiety, hopefulness and marital satisfaction of the barren men, Doctoral dissertation, counseling major, Islamic Azad University, Tehran, Sciences and Research branch.

[10] Hyer, L., Stanger, E., \& Boudewyns, P. (1999). The interaction of post-traumatic stress disorder and depression among older combat veterans. Journal of Clinical Psychology, 55: 1073-1083.

[11] Khaledian, M., Gharibi, H., Gholizade, Z., \& Shakeri, R. (2013). Effectiveness of the CBT on reducing depression and increasing life expectancy in the syndrome of empty net, Periodical of counseling and family psychotherapy, 3(2): 261-279. 
[12] Kheirkhah, Z. (2010). Effectiveness of CBT in increasing hopefulness and reducing depression of the wives of the martyrs, M.A. thesis, Islamic Azad University, Tehran, Sciences and Research branch.

[13] Lihi, R. (2008). Techniques of cognitive therapy, Trans by Ladan Fata, Tehran: Danje publication.

[14] Roshan, R., \& Shakeri, R. (2010). Investigating the extent of depression among the wives of martyrs in Province of Tehran by using the special scale for measuring depression among the wives if the martyrs, Journal of Ofoghe Danesh, 1(16): 12-24.

[15] Siegle, G., Steinhart, S., Friedman, E., Thompson, W., \& Thase, M. (2011). Remission Prognosis for cognitive therapy for Recurrent Depression Using the Pupil: Utility and Neural Correlates Biological Psychiatry, 69(8): 726-733.

[16] Smits, J., Minhajuddin, A., \& Jarret, R. (2009). Cognitive therapy for depressed adults with co morbid social phobia. Journal of Affective Disorders, 114: 271-278.

[17] Vafaei, T., \& Khosravi, S. (2009). Comparison of mental health of the wives of the amputee veterans and those of the normal people, Journal of Janbaz Medics, 1(4): 9-13.

[18] Zisook, S., Paulus, M., Shuchter, S. R., \& Judd, L. L. (1997). The many faces of depression following spousal bereavement. Journal of Affective Disorders, 45: 85- 95. 